This document is confidential and is proprietary to the American Chemical Society and its authors. Do not copy or disclose without written permission. If you have received this item in error, notify the sender and delete all copies.

\title{
Uptake and Metabolism of Human Pharmaceuticals by Fish - A Case Study with the Opioid Analgesic Tramadol
}

\begin{tabular}{|r|l|}
\hline Journal: & Environmental Science \& Technology \\
\hline Manuscript ID & es-2017-03441k.R1 \\
\hline Manuscript Type: & Article \\
\hline Date Submitted by the Author: & n/a \\
\hline List of Authors: & $\begin{array}{l}\text { Tanoue, Rumi; Ehime University, Center for Marine Environmental Studies } \\
\text { (CMES) } \\
\text { Margiotta-Casaluci, Luigi; Brunel University London, Institute of } \\
\text { Environment, Health and Societies } \\
\text { Huerta, Belinda; Brunel University London, Institute of Environment, } \\
\text { Health and Societies } \\
\text { Runnalls, Tamsin; Brunel University, Institute for the Environment } \\
\text { Nomiyama, Kei; Ehime University, Center for Marine Environmental Studies } \\
\text { (CMES) } \\
\text { Kunisue, Tatsuya; Ehime University, Center for Marine Environmental } \\
\text { Studies (CMES) } \\
\text { Tanabe, Shinsuke; Ehime University, Center for Marine Environmental } \\
\text { Studies (CMES) } \\
\text { Sumpter, John; Brunel University, Institute for the Environment }\end{array}$ \\
\hline
\end{tabular}


1 Uptake and Metabolism of Human Pharmaceuticals by Fish

2

3

4

5

6

7
*Address correspondence to: Rumi Tanoue, Ph.D.

Centre for Marine Environmental Studies (CMES), Ehime University, 2-5, Bunkyo-cho, Matsuyama, Ehime 790-8577, Japan.

TEL/FAX: +81-89-927-8162

E-mail address: rumi.tanoue.lw@gmail.com 


\section{ABSTRACT}

Recent species-extrapolation approaches to predict the potential effects of pharmaceuticals present in the environment on wild fish are based on the assumption that pharmacokinetics and metabolism in humans and fish are comparable. To test this hypothesis, we exposed fathead minnows to the opiate pro-drug tramadol and examined uptake from the water into the blood and brain, and metabolism of the drug into its main metabolites. We found that plasma concentrations could be predicted reasonably accurately based on the lipophilicity of the drug, once the $\mathrm{pH}$ of the water was taken into account. The concentrations of the drug and its main metabolites were higher in the brain than in the plasma, and the observed brain/plasma concentration ratios were within the range of values reported in mammalian species. This fish species was able to metabolise the pro-drug tramadol into the highly active metabolite $O$-desmethyl tramadol and the inactive metabolite $\mathrm{N}$-desmethyl tramadol in a similar manner to mammals. However, we found that concentration ratios of $O$-desmethyl tramadol to tramadol were lower in the fish than values in most humans administered the drug. Our pharmacokinetic data of tramadol in fish help bridge the gap between widely available mammalian pharmacological data and potential effects on aquatic organisms, and highlight the importance of understanding drug uptake and metabolism in fish to enable the full implementation of predictive toxicology approaches. 


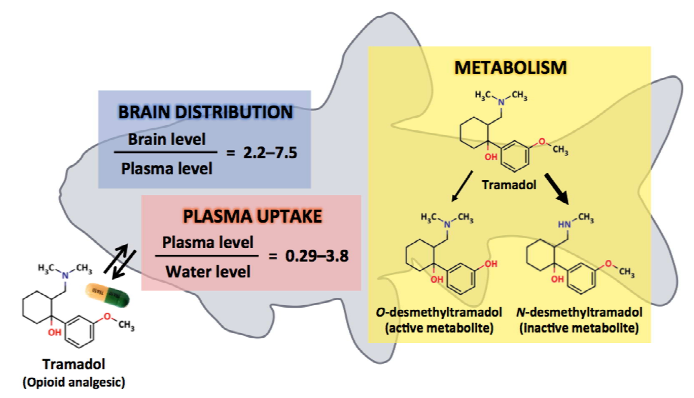

Table of Contents (TOC) Art

54 


\section{INTRODUCTION}

It is now well known that many different human pharmaceuticals are present in the rivers of essentially all countries. This is a consequence of them, and their metabolites, being excreted by people into the sewage system and not being completely removed by wastewater treatment. ${ }^{1-4}$ Many of these pharmaceuticals can be found in aquatic organisms such as fish. ${ }^{5-10}$ Due to the impracticality of testing all human pharmaceuticals ${ }^{11,12}$ on fish and other aquatic organisms, which is a consequence of the large amount of time and resources that would be required to do so, as well as the ethical issues around conducting those ecotoxicity tests, the way forward has to be to reach a stage where it is possible to accurately predict the degree of threat these biologically-active molecules (and their metabolites) pose to aquatic organisms. Key steps in making those reliable predictions are understanding the occurrence and concentrations of the pharmaceutical in the aquatic environment and factors influencing the degree of its uptake, distribution, and metabolism in the organism (pharmacokinetics), as well as being able to predict the likely effects (pharmacodynamics). It is well known that the uptake of pharmaceuticals is mainly influenced by their physicochemical properties, ${ }^{13-17}$ and that the likelihood of effects is governed primarily by the presence or absence of the drug target. ${ }^{18}$ However, the steps between these two factors - namely internal distribution and metabolism in fish - are much less well understood. Understanding whether or not fish metabolise pharmaceuticals, and if so to what, is crucial to accurate predictions of risk, for a number of reasons. One is that many pharmaceuticals are detoxified (i.e., made inactive) by metabolism: the parent molecule is active, but the metabolites are not. Another is the opposite: some pharmaceuticals (the so-called pro-drugs) are inactive until they are metabolised, with the efficacy of the drug dependent on metabolism of the parent molecule into the pharmacologically active molecule(s). Finally, the possibility exist that fish, and other aquatic organisms, might metabolise pharmaceuticals differently to humans; if they did, different metabolites, which could have unique pharmacological activities, and hence lead to unanticipated effects, could be produced. Hence, if the read-across hypothesis ${ }^{13,19}$ is to be maximally useful in aiding the prediction of the effects of pharmaceuticals on non-target 
100 species such as fish, drug metabolism in these species needs to be understood. This study was

101 designed to improve our knowledge of the uptake and metabolism of pharmaceuticals by fish

102 through studying how they metabolise the pro-drug tramadol.

103 Tramadol, which is an opioid analgesic, is widely used to treat moderate to severe pain, acting as

104 an agonist of $\mu$-opioid receptors as well as being a serotonin and noradrenaline reuptake inhibitor.

105 As tramadol is only partially removed in conventional wastewater treatment plants (WWTPs), ${ }^{20-23}$

106 the compound has frequently been detected in surface waters around the world, at concentrations in

107 the range of $n g \mathrm{~L}^{-1}$ to low $\mu \mathrm{g} \mathrm{\textrm {L } ^ { - 1 } \cdot 2 , 2 2 , 2 4 , 2 5}$ Some researchers have reported more than ten times

108 higher concentrations of tramadol in South Wales (United Kingdom) than other regions - the

109 highest concentrations were $98 \mu \mathrm{g} \mathrm{L}^{-1}$ and $7.7 \mu \mathrm{g} \mathrm{L}^{-1}$ in wastewater effluents ${ }^{20}$ and surface waters ${ }^{26}$,

110 respectively. Likewise, extremely high concentrations of tramadol ranging from 10 to $100 \mu \mathrm{g} \mathrm{L}^{-1}$

111 were found in surface water from Cameroon. ${ }^{27}$ In widely used biodegradability tests from the

112 OECD series, tramadol was characterized as a "not readily biodegradable" substance. ${ }^{28}$ A

113 dissipation half-life of 49 days in degradation experiments with a bench-scale flume was previously

114 reported. $^{29}$

115 The present study aimed at investigating the partitioning of tramadol between test water and fish

116 blood, and between blood and brain in a teleost fish, the fathead minnow (Pimephales promelas),

117 after 23-24 days of chronic waterborne exposure to tramadol. An additional aim was to investigate

118 tramadol metabolism in fish by measuring the active metabolite $O$-desmethyl tramadol (T-M1) and

119 the inactive metabolite $N$-desmethyl tramadol (T-M2), and to compare metabolism of tramadol in

120 fish and mammalian species. In humans, metabolism of tramadol is mainly mediated by

121 cytochrome P450 (CYP) 2D6, which transforms tramadol into the active metabolite T-M1, and by

122 CYP2B6 and CYP3A4, which transforms tramadol into the inactive metabolite T-M2. ${ }^{30}$

123 Considering the existing uncertainties around the evolutionary aspects and functional diversity of

124 these enzymes (especially CYP2 subfamilies) in teleost fish, ${ }^{31}$ generating novel drug-metabolism

125 data in fish can provide important information on the functional conservation of these metabolic 
126 properties across species, and support species-extrapolation and predictive

127 pharmacology/toxicology approaches. In order to facilitate data interpretation, we also quantified

128 the metabolism of the antidepressant fluoxetine in the same species, and used it as a reference.

129 Fluoxetine is metabolised to the equipotent active metabolite norfluoxetine through

$130 N$-demethylation by CYP 2D6, 2C9, 2C19, and 3A4 in humans. ${ }^{32}$

131

132 MATERIALS AND METHODS

133 Chemicals. Tramadol hydrochloride was purchased from Sigma-Aldrich (Dorset, UK) with purity 134 higher than 99\% (product number 42965-5G-F, lot number BCBN4547V). Fluoxetine 135 hydrochloride was purchased from Sigma-Aldrich (Dorset, UK) with purity higher than 99.9\% 136 (product number PHR1394, lot number LRAA1901). N, N-dimethylformamide (DMF) was 137 obtained from Fisher Scientific (Loughborough, UK). Liquid chromatography-mass spectrometry 138 grade methanol, acetonitrile, acetic acid, and ammonium acetate (98\%) were purchased from Wako 139 Chemicals (Osaka, Japan). Ultrapure water (Milli-Q water) was obtained using a Direct-Q3 water 140 purification system (Millipore, Japan). Oasis HLB cartridges (30 mg, $1 \mathrm{~mL}$ ) were purchased from 141 Waters (Milford, MA, USA). Analytical certified solution standards of cis-tramadol hydrochloride, $142 O$-desmethyl-cis-tramadol hydrochloride, $N$-desmethyl-cis-tramadol hydrochloride, fluoxetine 143 hydrochloride, and norfluoxetine oxalate, were purchased from Sigma-Aldrich (St. Louis, MO, 144 USA). Internal standard (IS) solutions of tramadol- ${ }^{13} C-d_{3}$ hydrochloride, $145 O$-desmethyl-cis-tramadol- $d_{6}$ hydrochloride, fluoxetine- $d_{6}$ hydrochloride, and norfluoxetine- $d_{6}$ 146 oxalate, were purchased from Sigma-Aldrich (St. Louis, MO, USA).

148 Test Fish. Adult fathead minnows (Pimephales promelas), approximately seven months old, $2.6 \pm$ $1490.53 \mathrm{~g}$ average weight, and $5.4 \pm 0.30 \mathrm{~cm}$ average length, were supplied from breeding stocks 150 maintained at Brunel University London, UK. Ten days before the beginning of chemical dosing, 151 sexually mature males were transferred into the flow-through systems for acclimation to the test 
152 conditions. Fish were fed three times per day: once with adult brine shrimp (Tropical Marine 153 Centre, Gamma irradiated), and twice with flake food (King British Tropical flake food), 154 throughout the experiment. This study was carried out under Project and Personnel Licences 155 granted by the UK Home Office, which follows the United Kingdom Animals (Scientific 156 Procedures) Act 1986, and the European Animal Directive 2010/63/EU.

157

Experimental Design. A preliminary short-term exposure test with two different $\mathrm{pH}$ conditions was performed before the chronic 23-24 days exposure test, to assess the effect of water $\mathrm{pH}$ on uptake of tramadol by fish. Thirty-two fish were transferred into 2 glass tanks ( $n=16$ in each tank) which were filled with $20 \mathrm{~L}$ of thermostatically-heated dechlorinated tap water adjusted to $\mathrm{pH} 8.1 \pm$ 0.09 (short-term treatment A) or $8.5 \pm 0.09$ (short-term treatment B) by addition of $0.1 \mathrm{M} \mathrm{NaOH}$. Water concentrations of tramadol in tanks were nominally set at $100 \mu \mathrm{g} \mathrm{L}^{-1}$ by adding $4 \mathrm{~mL}$ of tramadol solution $\left(500 \mathrm{mg} \mathrm{L}^{-1}\right.$ in DMF: Milli-Q water $\left.(1: 4, \mathrm{v} / \mathrm{v})\right)$ to $20 \mathrm{~L}$ of dechlorinated tap water. Test water in tanks was partially renewed (50\%) every $12 \mathrm{~h}$, resulting in approximately $70 \%$ daily replacement. Four fish were sampled from each tank at 12, 24, 48, and $72 \mathrm{~h}$, for analysis of tramadol in plasma.

The 23-24 days chronic exposure was carried out using a continuous flow-through system comprising twelve 20.5 L glass tanks (dimensions: $45(1) \times 24(w) \times 19(d) \mathrm{cm})$. The test was run at a photoperiod of $16 \mathrm{~h}$ light: $8 \mathrm{~h}$ of dark, with $20 \mathrm{~min}$ dawn/dusk transition periods. During the experiment, the temperature of water, $\mathrm{pH}$, and dissolved oxygen concentrations were maintained at $25 \pm 1^{\circ} \mathrm{C}, 7.8 \pm 0.19(7.5-8.2)$, and $6.0-8.0 \mathrm{mg} \mathrm{L} \mathrm{L}^{-1}$, respectively. Thermostatically-heated dechlorinated tap water flowed into 12 glass mixing chambers at a rate of approximately $167 \mathrm{~mL}$ $\min ^{-1}\left(10 \mathrm{~L} \mathrm{~h}^{-1}\right)$, which supplied approximately 12 tank volumes per day to each test tank. The same mixing chambers also received stock solutions containing test chemicals delivered via peristaltic pumps at a rate of approximately $33 \mu \mathrm{L} \min ^{-1}\left(2 \mathrm{~mL} \mathrm{~h}^{-1}\right)$. The stock solutions containing test chemicals were prepared every four days in amber bottles with DMF: Milli-Q water $(1: 4, \mathrm{v} / \mathrm{v})$ as a 
178 carrier solvent. The final DMF concentration in the test water was approximately $0.004 \%$. Six

179 exposure treatment groups: water dilution control (WDC), solvent control containing $0.004 \%$ of

180 DMF (SC), $1 \mu \mathrm{g} \mathrm{L}^{-1}$ (TG-1), $10 \mu \mathrm{g} \mathrm{L}{ }^{-1}$ (TG-10), and $100 \mu \mathrm{g} \mathrm{L}^{-1}$ (TG-100) of tramadol, and $100 \mu \mathrm{g}$

$181 \mathrm{~L}^{-1}$ of fluoxetine (FG-100), were prepared. Each treatment group had two replicates (2 tanks). Eight

182 males were randomly allocated to the glass tanks, giving a total of 16 fish per treatment. The

183 concentrations of chemicals in the test water were chosen to cover both environmentally and

184 pharmacologically relevant concentrations. The highest water concentration $\left(100 \mu \mathrm{g} \mathrm{L}^{-1}\right)$ was

185 chosen in order to produce fish plasma levels of tramadol proximate to the human therapeutic

186 plasma concentration range $\left(100-300 \mathrm{ng} \mathrm{mL}^{-1}\right)^{33}$. Water samples $(1 \mathrm{~mL})$ were collected in

187 polypropylene tubes on day- $0,1,2,4,7,10,14,16,19$, and 22 from all tanks, to measure the water

188 concentrations of test chemicals.

189 After the 23-24 days chemical exposure, all fish were individually anaesthetised with an 190 aqueous solution of ethyl 3-aminobenzoate methanesulfonate ( $0.5 \mathrm{~g} \mathrm{~L}^{-1}$ of MS-222 at $\left.\mathrm{pH} 7.5\right)$,

191 according to UK Home Office regulations. Fish blood was taken from the caudal vein using

192 heparinized capillary tubes. Blood samples were centrifuged $(8000 \times \mathrm{g}, 5 \mathrm{~min}, 4 \circ \mathrm{C})$ to obtain

193 plasma samples. The plasma samples were stored at $-80^{\circ} \mathrm{C}$ until chemical analysis. Standard length

194 and body weight of fish were measured, and then fish brain was collected, weighed, snap-frozen in

195 liquid nitrogen, and stored at $-80^{\circ} \mathrm{C}$ until subsequent analysis.

196

197 Chemical analysis. Detailed information on analytical procedures for identification and

198 quantification of tramadol and its metabolites T-M1 and T-M2, as well as fluoxetine and its

199 metabolite norfluoxetine in water, plasma, and brain samples, can be found in the Supporting

200 Information (SI). Briefly, 10 to 20 -fold diluted water samples were directly injected in an

201 instrument described below. Plasma samples $(10 \mu \mathrm{L})$ were subjected to protein precipitation with

202 IS solution, acetate buffer, and methanol. Following centrifugation, an aliquot of the supernatant

203 was diluted with Milli-Q water. Totally 20 to 500 -fold diluted plasma extracts were directly 
204 injected in an instrument described below. Brain samples (14-25 mg) were homogenized in IS 205 solutions, acetate buffer, methanol, and acetonitrile, subsequently subjected to protein precipitation 206 and ultrasonically extraction. Following centrifugation, an aliquot of the supernatant was diluted 207 with Milli-Q water. The water-diluted sample was loaded onto an Oasis HLB cartridge, the analytes 208 retained in the cartridge were then eluted with methanol. The solvent was evaporated and the 209 contents were reconstituted in methanol: Milli-Q water (4:6, v/v). Totally 20 to 2000-fold diluted brain extracts were injected in an instrument described below. Instrumental analysis was performed on an ultra-high-performance liquid chromatograph system (UFLC XR, Shimadzu, Japan) coupled to an AB Sciex Qtrap 5500 mass spectrometer (Applied Biosystems Sciex, Tokyo, Japan) operating in electrospray ionization (ESI) positive mode with multiple reaction monitoring (MRM).

Quality Assurance and Control (QA/QC). Target compound concentrations were determined by an isotope-dilution method. IS-corrected recovery rates of target compounds in plasma and brain of fish were determined by triplicate analyses of target compound-free fish tissues spiked with target compounds at 6 concentrations ranging from 0.1 to $10000 \mathrm{ng} \mathrm{mL}^{-1}$ plasma or $\mathrm{ng} \mathrm{g}^{-1}$ brain. Method detection limits (MDLs) were calculated from the standard deviation (SD) of nine replicate injections of the fortified tissue extracts (at the lowest concentrations spiked). IS-corrected recovery rates, precision, and MDLs for plasma and brain samples are shown in Supporting Information (Table S2 and S3). IS-corrected recovery rates ranged between $85.2 \%$ and $126 \%$, with relative standard deviations less than $15 \%$.

Prediction of Tramadol Concentration in Fish Plasma. A fish plasma model (FPM) has been proposed as a screening technique to estimate potential risk of pharmaceuticals to wild fish. ${ }^{19,34,35}$ In the FPM, drug plasma concentration is predicted using the theoretical partition coefficient between water and fish blood based on chemical lipophilicity. The predicted fish plasma 
230 plasma (human therapeutic plasma concentration ranges). However, the original fish blood-water

231 partitioning model was developed based on empirical data for neutral organochlorine compounds 232 such as polychlorinated biphenyls (PCBs) that are relatively stable in animal tissues. ${ }^{36}$ The original 233 fish blood-water partition coefficient was described by the following equation ${ }^{36}$

$$
P_{\mathrm{BW}}=\left(10^{0.73 \log K o \mathrm{w}} \times 0.16\right)+0.84
$$

235

236

237

238

239

240

where $P_{\mathrm{BW}}$ is the equilibrium blood-water partition coefficient, $K_{\mathrm{ow}}$ is the octanol-water partition coefficient. This equation was developed using empirical data from rainbow trout, and the terms of 0.16 and 0.84 represent the organic (lipids and proteins) and aqueous fractions in rainbow trout whole blood, respectively.

In recent years, $\mathrm{pH}-$ dependent octanol-water partition coefficient $\left(D_{\mathrm{ow}}\right)$ has been proposed as an alternative to $K_{\mathrm{ow}}$, to more accurately reflect partitioning for ionisable pharmaceuticals. ${ }^{5,37-44}$ By using $D_{\text {ow }}$ as a parameter, various authors have successfully predicted the plasma drug concentrations within a log unit deviation for fluoxetine ${ }^{40}$, sertraline ${ }^{38}$, propranolol ${ }^{45}$, and oxazepam $^{39}$. On the other hand, liposome--water partition coefficient $\left(K_{\text {lipw }}\right)$ has been expected to be a more accurate descriptor than $K_{\text {ow }}$ to estimate bioconcentration of ionisable chemicals in organisms. ${ }^{46-49}$ The $K_{\text {lipw }}$ can be converted into $\mathrm{pH}$-dependent liposome-water partition coefficient $\left(D_{\text {lipw }}\right){ }^{46}$

In the present study, steady-state plasma bioconcentration factors $\left(\mathrm{BCF}_{\text {plasma }}\right.$ : fish plasma/water concentration ratios) of tramadol in fathead minnows were predicted by the concept of $P_{\mathrm{BW}}$ described above, based on an assumption that the tramadol concentration in fish plasma and whole blood is approximately equal, as blood-to-plasma ratio was previously determined at $1.09 \pm 0.02$ in healthy male volunteers. ${ }^{50}$ The aqueous fraction in the whole blood of fathead minnow $(87.6 \%)$ is slightly higher than that in rainbow trout $(83.9 \%) .{ }^{51}$ Thus, the original equation was modified based on the difference in blood composition between rainbow trout and fathead minnow, and the following equations were obtained.

$$
\mathrm{BCF}_{\text {plasma }}=\left(10^{0.73 \log K \text { ow }} \times 0.12\right)+0.88
$$


256

257

258

260

261

262

263

264

265

266

267

268

269

270

272

273

274

275

276

277

278

279

280

281

$$
\begin{gathered}
\mathrm{BCF}_{\text {plasma }}=\left(10^{0.73 \log D \text { ow }} \times 0.12\right)+0.88 \\
\mathrm{BCF}_{\text {plasma }}=\left(10^{0.73 \log D \text { lipw }} \times 0.12\right)+0.88
\end{gathered}
$$

The $\mathrm{pH}$-dependent $D_{\text {ow }}$ was calculated by

$$
D_{\text {ow }}=f_{\text {neutral }} \times K_{\text {ow (neutral) }}+f_{\text {ion }} \times K_{\text {ow (ion) }}
$$

where $f_{\text {neutral }}$ and $f_{\text {ion }}$ are the fractions of the neutral and ion species at the study $\mathrm{pH}$, respectively, and $K_{\mathrm{ow} \text { (neutral) }}$ and $K_{\mathrm{ow} \text { (ion) }}$ are the respective $K_{\mathrm{ow}}$ values. The relationship between $f_{\text {ion }}$ and $f_{\text {neutral }}$ is defined by

$$
f_{\text {ion }}=f_{\text {neutral }} \times 10^{|p H-p K a|}
$$

It was assumed that $\log K_{\text {ow (ion) }}$ is $3.5 \log$ units lower than the corresponding $\log K_{\text {ow (neutral). }}{ }^{52}$ Mean $\mathrm{pH}$ values measured in each tank were used for the calculation. Although various programs have been developed to predict $\log K_{\mathrm{ow}}$, each program uses different algorithms. Given the uncertainty of calculating $\log K_{\mathrm{ow}}$, we used the lowest and the highest $\log K_{\mathrm{ow}}$ values (2.45 and 3.01, respectively) from databases and reported $\mathrm{pKa}$ value of 9.41 to predict $\mathrm{BCF}_{\text {plasma. }}$. Physicochemical properties of tramadol were summarized in Table S4 in the supporting information. The pH-dependent $\log D_{\text {lipw }}$ was calculated by

$$
D_{\text {lipw }}=f_{\text {neutral }} \times K_{\text {lipw (neutral) }}+f_{\text {ion }} \times K_{\text {lipw (ion) }}
$$

where $f_{\text {neutral }}$ and $f_{\text {ion }}$ are the fractions of the neutral and ion species at the study $\mathrm{pH}$, respectively, and $K_{\text {lipw (neutral) }}$ and $K_{\text {lipw (ion) }}$ are the respective $K_{\text {lipw }}$ values. The $K_{\text {lipw (neutral) was calculated with the }}$ PP-LFER equation ${ }^{53}$ for $\log K_{\left.\text {lipw (neutral, } 25^{\circ} \mathrm{C}\right)}=0.48+0.55 \mathrm{~L}-0.95 \mathrm{~S}-0.05 \mathrm{~A}-4.02 \mathrm{~B}+1.65 \mathrm{~V}$ and chemical parameters taken from the UFZ-LSER database v $3.1^{54}$. The $K_{\text {lipw (ion) was calculated with }}$ COSMOmic extended for the description of charged organic chemicals via the implementation of the membrane bilayer potential. ${ }^{37,46}$ Eventually, measured tramadol concentrations in plasma of fathead minnows were compared with the concentrations predicted by the $\mathrm{BCF}_{\text {plasma }}$ estimated using three different chemical lipophilic parameters $\left(K_{\text {ow }}, D_{\text {ow }}\right.$, and $\left.D_{\text {lipw }}\right)$, i.e. equations (2), (3), (4). Mean tramadol water concentration measured in each tank was used for the prediction. 
282 Statistical Analysis. Normal distribution and homogeneity of variance were tested with

283 Shapiro-Wilk and Levene's tests, respectively. For data with normal distribution and variance

284 homogeneity, parametric tests were applied. If the data did not show a normal distribution, 285 nonparametric tests were applied. Eventually, comparing $\mathrm{BCF}_{\text {plasma }}$ values between short-term 286 treatment $\mathrm{A}$ and B, non-parametric Mann-Whitney-Wilcoxon rank sum tests were conducted. 287 Non-parametric Kruskal-Wallis test followed by Steel-Dwass test were performed to compare the $288 \mathrm{BCF}_{\text {plasma }}$ from different water $\mathrm{pH}$ conditions. For assessing the relationship between the 289 concentration of tramadol in plasma and brain, nonparametric Spearman's rank correlation 290 coefficients were calculated. Parametric one-way ANOVA followed by a Tukey's HSD test was 291 conducted to compare brain/plasma tramadol concentration ratios among treatments. For assessing 292 the relationship between plasma fluoxetine levels and norfluoxetine/fluoxetine concentration ratios, 293 nonparametric Spearman's rank correlation coefficients were calculated. A $p$-value of $<0.05$ was 294 considered statistically significant. All statistical analyses were conducted using the open source 295 statistical software R 3.3.2 GUI 1.68 Mavericks build (7288) (http://www.r-project.org/).

\section{RESULTS AND DISCUSSION}

298

299

300

301

Preliminary Experiment to Assess the Influence of Water pH on Fish Uptake of Tramadol. Measured concentrations of tramadol in test water were $96 \pm 3.9 \mu \mathrm{g} \mathrm{L} \mathrm{L}^{-1}$ and $93 \pm 4.4 \mu \mathrm{g} \mathrm{L} \mathrm{L}^{-1}$ for short-term treatment A and B, respectively. Time-course of tramadol concentrations in fish plasma are presented in Figure 1 (A). Although mean plasma concentrations in both treatment A (at pH 8.1) and $\mathrm{B}$ (at $\mathrm{pH} 8.5$ ) increased with the exposure time, the data from $24 \mathrm{~h}$ to $72 \mathrm{~h}$ did not show significant changes. Assuming near steady-state condition, measured plasma data from 24, 48 and

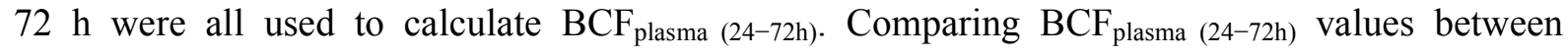
treatment A (median: 1.4, $n=12$ ) and treatment B (median: 1.8, $n=12$ ), a statistically significant difference was observed $(p=0.019)$. Even if plasma tramadol concentrations did not reach steady-state conditions, it can be speculated that $\mathrm{BCF}_{\text {plasma }(24-72 \mathrm{~h})}$ values reflected the difference in 
308 fish uptake rates between treatment A and B. For ionisable chemicals, it is well known that

309 ionization can reduce their uptake into organisms owing to a decrease in their lipophilicity and

310 accompanying membrane permeability. As tramadol is a weakly basic compound and has a $\mathrm{pKa}$

311 value of 9.41 (amino group), theoretically, 95\% and $89 \%$ of tramadol are considered to be

312 positively charged at $\mathrm{pH} 8.1$ and 8.5 , respectively.

313

314 Tramadol and Fluoxetine Concentrations in Test Water for 23-24 Days exposure. None of the 315 targeted chemicals were detected in any control (WDC and SC) samples. Tramadol was not 316 detected in any fluoxetine-treated water samples, and fluoxetine was not detected in any 317 tramadol-treated water samples. Tramadol water concentrations (mean $\pm \mathrm{SD}, n=18$ ) measured 318 throughout the experiment for TG-1, TG-10, and TG-100 treatment were $1.1 \pm 0.053 \mu \mathrm{g} \mathrm{L}^{-1}, 9.9 \pm$ $3190.65 \mu \mathrm{g} \mathrm{L}^{-1}$, and $98 \pm 5.2 \mu \mathrm{g} \mathrm{L}^{-1}$, respectively. Fluoxetine water concentration (mean $\pm \mathrm{SD}, n=18$ ) 320 measured throughout the experiment for the FG-100 treatment was $94 \pm 8.5 \mu \mathrm{g} \mathrm{L} \mathrm{L}^{-1}$. Measured 321 concentrations were all within $\pm 20 \%$ of the nominal values. Inter-tank variabilities were also 322 within $\pm 20 \%$.

Concentrations of Tramadol and Its Metabolite in Fish Plasma After 23-24 Days Exposure.

325 None of the targeted chemicals were detected in any control (WDC and SC) samples. Tramadol fish 326 plasma concentrations (mean $\pm \mathrm{SD}, n=16$ ) measured after the 23-24 days chronic exposure for 327 TG-1, TG-10, and TG-100 treatment groups were $1.0 \pm 0.32 \mathrm{ng} \mathrm{mL}^{-1}, 5.9 \pm 2.9 \mathrm{ng} \mathrm{mL}{ }^{-1}$, and $46 \pm$ $32812 \mathrm{ng} \mathrm{mL} \mathrm{m}^{-1}$, respectively. Within each treatment, the difference between the minimum and 329 maximum plasma concentrations was up to 4-fold. Plasma tramadol concentrations of all fish 330 exposed to waterborne tramadol at $98 \mu \mathrm{g} \mathrm{L} \mathrm{L}^{-1}$ were slightly below the human therapeutic plasma 331 concentration range $\left(100-300 \mathrm{ng} \mathrm{mL}^{-1}\right)^{33}$. Active metabolite T-M1 plasma concentrations (mean \pm $332 \mathrm{SD}, n=16$ ) measured for TG-10 and TG-100 treatment groups were $0.88 \pm 0.60 \mathrm{ng} \mathrm{mL} \mathrm{L}^{-1}$ and $3.8 \pm$ $3330.99 \mathrm{ng} \mathrm{mL}^{-1}$, respectively. All plasma samples in TG-1 treatment group had T-M1 concentrations 
334 below the MDL value $\left(0.14 \mathrm{ng} \mathrm{mL}^{-1}\right)$. Plasma T-M1 concentrations $\left(3.8 \pm 1.0 \mathrm{ng} \mathrm{mL} \mathrm{m}^{-1}\right)$ of fish 335 exposed to tramadol at $100 \mu \mathrm{g} \mathrm{L}^{-1}$ were approximately 10 times lower than effective plasma T-M1 336 concentrations $\left(40 \pm 30 \mathrm{ng} \mathrm{mL}^{-1}\right)$ reported in humans ${ }^{55}$. Inactive metabolite T-M2 plasma 337 concentrations (mean $\pm \mathrm{SD}, n=16$ ) measured for TG-1, TG-10, and TG-100 treatment groups were $3380.48 \pm 0.21 \mathrm{ng} \mathrm{mL}^{-1}, 1.2 \pm 0.43 \mathrm{ng} \mathrm{mL}^{-1}$, and $7.2 \pm 1.7 \mathrm{ng} \mathrm{mL}^{-1}$, respectively.

340 Measured vs. Predicted Fish Plasma Concentrations and $\mathbf{B C F}_{\text {plasma }}$ of Tramadol. Measured 341 plasma concentrations were compared with the concentrations predicted by the FPM (Figure 1 (B)). 342 When $\mathrm{pH}$-dependent chemical lipophilicity $\left(D_{\text {ow }}\right.$ or $\left.D_{\text {lipw }}\right)$ was used for the prediction, measured 343 median values were 2-6 times lower than predicted values. When using FPM for estimating the 344 potential risk of pharmaceuticals, an overestimated prediction would not be serious from the 345 viewpoint of precautionary principle. Nevertheless, the disagreement between measured and 346 predicted plasma tramadol concentrations in fathead minnows might be due to differences in the 347 existence form in the blood and/or hepatic clearances, between tramadol and PCBs. In fact, plasma 348 protein binding of tramadol in human was reported to be approximately $20 \%{ }^{56}$, while lipid-soluble 349 PCBs can be highly retained in the blood lipids. For the clearance of tramadol, we found its 350 metabolites T-M1 and T-M2, with the concentration ratios of tramadol: T-M1 + T-M2 $=4: 1$ in 351 plasma of fathead minnows. As it can be presumed that biotransformation of tramadol in fish 352 occurs much faster than PCBs, metabolism of tramadol by fathead minnow is likely involved in the 353 disagreement between measured and predicted plasma tramadol concentrations. Accounting for the 354 protein binding and metabolism, $\mathrm{BCF}_{\text {plasma }}$ of tramadol can be predicted by

$$
\mathrm{BCF}_{\text {plasma }}=\left[\left(10^{0.73 \log \alpha} \times 0.12 \times f_{\mathrm{bp}}\right)+0.88\right] \times f_{\text {parent }}(8)
$$

356 where $\alpha$ is $D_{\text {ow }}$ or $D_{\text {lipw }}$, the terms of 0.12 and 0.88 represent the organic and aqueous fractions in 357 fathead minnow whole blood, respectively, and $f_{\mathrm{bp}}$ is the fraction bound to proteins (value 358 measured in human plasma: 0.20), $f_{\text {parent }}$ is the fraction of parent compound tramadol 359 (tramadol/tramadol + TM-1 + TM-2 concentration ratio in plasma of fathead minnow: 0.80 ). When 
360 comparing measured tramadol concentrations in plasma of fathead minnow with the concentrations

361 predicted by the $\mathrm{BCF}_{\text {plasma }}$ estimated using the equation (8), only $0.86-1.8$ fold differences were 362 observed. In the present study, only 2 metabolites (i.e., TM-1 and TM-2) in fathead minnow were 363 measured and the $f_{\text {parent }}$ of 0.80 was applied as a provisional value. The actual value should be 364 lower than 0.80 , because 23 metabolites of tramadol were previously identified in human urine. ${ }^{57}$ 365 Additionally, several study have reported that $25-30 \%$ of an oral dose is excreted as unchanged 366 drug in the urine of human, whereas $55-60 \%$ of an oral dose is excreted as metabolites. ${ }^{56}$

367 Measured $\mathrm{BCF}_{\text {plasma }}$ of tramadol for 23-24 days exposure are shown in Figure 1 (C). These $368 \mathrm{BCF}_{\text {plasma }}$ values, ranging from 0.29 to 1.6 for fathead minnows, were similar to or slightly lower 369 than those for rainbow trout (min-max: 2.3-3.3) exposed to treated wastewater in Sweden ${ }^{58}$. 370 Measured $\mathrm{BCF}_{\text {plasma }}$ values were the highest for TG-1 treatment group, followed by TG-10 and 371 TG-100 treatment groups. Combining results from preliminary short-term and 23-24 days chronic

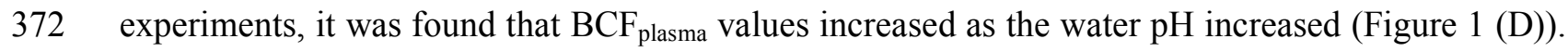
373 The lowest (median $\mathrm{BCF}_{\text {plasma }}$ : 0.44) and the highest (median $\mathrm{BCF}_{\text {plasma }}$ : 1.8) values were found at $374 \mathrm{pH} 7.6$ and 8.5, respectively. Theoretically, $99 \%$ and $89 \%$ of tramadol are considered to be 375 positively charged at $\mathrm{pH} 7.6$ and 8.5 , respectively. Our result supports previous studies ${ }^{5,38,42,59-61}$, 376 highlighting the importance of taking the water $\mathrm{pH}$ influence into account when $\mathrm{BCF}_{\text {plasma }}$ of 377 ionisable chemicals are estimated. From the viewpoint of environmental risk assessment for basic 378 chemicals, using water-based threshold values from in vivo tests at only neutral water $\mathrm{pH}$ can lead 379 to underestimation of their actual risks in natural alkaline surface waters, as pointed out by Boström 380 et al. $(2015)^{62}$.

Tramadol and Its Metabolite Concentrations in Fish Brain After 23-24 Days Exposure. None 383 of the targeted chemicals were detected in any control (WDC and SC) samples. Tramadol brain 384 concentrations (mean $\pm \mathrm{SD}, n=16$ ) measured after the 23-24 days exposure for TG-1, TG-10, and 385 TG-100 treatment groups were $4.6 \pm 1.4 \mathrm{ng} \mathrm{g}^{-1}, 26 \pm 10 \mathrm{ng} \mathrm{g}^{-1}$, and $200 \pm 49 \mathrm{ng} \mathrm{g}^{-1}$, respectively. 
$\mathrm{T}-\mathrm{M} 1$ brain concentrations (mean $\pm \mathrm{SD}, n=16$ ) measured for TG-1, TG-10, and TG-100 treatment

387 groups were below the MDL value $\left(0.56 \mathrm{ng} \mathrm{g}^{-1}\right), 1.4 \pm 0.40 \mathrm{ng} \mathrm{g}^{-1}$, and $11 \pm 3.5 \mathrm{ng} \mathrm{g}^{-1}$, respectively.

388 T-M2 brain concentrations (mean $\pm \mathrm{SD}, n=16$ ) measured for TG-1, TG-10, and TG-100 treatment 389 groups were $0.73 \pm 0.17 \mathrm{ng} \mathrm{g}^{-1}, 2.6 \pm 0.75 \mathrm{ng} \mathrm{g}^{-1}$, and $24 \pm 7.8 \mathrm{ng} \mathrm{g}^{-1}$, respectively. Recent results 390 from an in vitro human blood-brain barrier model and an in vivo rodent study have shown that 391 tramadol is actively transported from blood to brain by a proton-coupled organic cation antiporter 392 located in the blood-brain barrier. ${ }^{63}$ When examining a relationship between brain and plasma 393 individual concentrations for tramadol, T-M1, and T-M2 (Figure 2 (A)), strong positive correlations 394 were shown for all these chemicals $(r=0.83-0.97, p<0.001)$. Brain/plasma tramadol concentration 395 ratios were consistent among treatments (Figure $2(\mathrm{~B}))(p=0.86)$, showing a dose-independent 396 manner. These concentration ratios (min-max: 2.2-7.5) were similar to those reported for rodents 397 (min-max: 1.3-7.3) ${ }^{64-66}$. The similarity in brain/plasma tramadol concentration ratios between fish 398 and rodents supports the species-extrapolation and predictive pharmacology/toxicology 399 approaches $^{13}$. On the other hand, dose-dependent increases in brain/plasma concentration ratios 400 were observed for both T-M1 $(p=0.010)$ and T-M2 $(p=0.0001)$. The reason is unclear, but metabolism of tramadol into T-M1 and T-M2 might be induced in the brain of higher dose groups due to higher tramadol concentrations in the brain. As another possible reason, the protein-unbound (free) T-M1 and T-M2 in plasma, which can penetrate the blood-brain barrier, might increase by the reduction of plasma protein binding sites available for these metabolites because of the increase in plasma tramadol concentrations. However, our fish plasma concentration data represents the total

406 (both protein-bound and unbound) tramadol levels. Measurement of free tramadol, T-M1, and T-M2 407 in fish plasma will be needed to verify whether or not high dose of tramadol can increase amount of 408 free T-M1 and T-M2. Interestingly, brain/plasma T-M1 concentration ratios (min-max: 0.59-5.9) 409 were greater than those reported for rodents (min-max: $0.23-1.3)^{64,65}$.

411 A Comparison of Fish Metabolic Data with Mammalian Data. A comparison of 
412 metabolites/tramadol concentration ratios in plasma of fish with literature values reported in plasma 413 of various species including human beings, rodents, cats, and dogs is shown in Table S5 414 (Supporting Information) and Figure 3 (A). T-M1/tramadol concentration ratios, which were 0.087 $415 \pm 0.028($ mean $\pm \mathrm{SD}, n=16)$ in plasma of fish exposed to $98 \mu \mathrm{g} \mathrm{L} \mathrm{L}^{-1}$ of tramadol, were $2-6$ times 416 lower than literature values $(0.17-0.52)$ reported in general humans ${ }^{67-70}$. Meanwhile, the $417 \mathrm{~T}-\mathrm{M} 2 /$ tramadol concentration ratio, which was $0.16 \pm 0.031$ (mean $\pm \mathrm{SD}, n=16)$ in plasma of fish 418 exposed to $98 \mu \mathrm{g} \mathrm{L}^{-1}$ of tramadol, was quite similar to literature values $(0.074-0.14)$ reported in 419 humans ${ }^{68-70}$. Interestingly, T-M1/tramadol concentration ratios measured in fish are comparable to 420 those previously reported in a human who was classified as a CYP 2D6 poor metabolizer ${ }^{67}$. 421 Although fathead minnows are able to metabolize tramadol as humans do, the apparently slower 422 metabolism of tramadol into the active metabolite T-M1 indicates that this species of fish is less 423 capable of metabolising tramadol into T-M1 than most humans; this might result in decreased 424 analgesic efficacy of the drug. A recent publication ${ }^{71}$ has shown that T-M2 levels greater than T-M1 425 levels were present in the brain of zebrafish (Danio rerio) after administration of a single 426 intramuscular dose of tramadol, supporting the results of our study, although that paper is not 427 concerned with the environmental impact of pharmaceuticals, nor the relevance of drug metabolism 428 to any potential impact. As shown in Table S5 and Figure 3 (A), the metabolites/tramadol concentration ratios are significantly variable among animal species; differences in the T-M1/tramadol concentration ratio occur not only between fish and humans, but also between 431 different mammalian species. In rodents, high metabolic rates of tramadol into T-M1 compared 432 with those in humans have been reported, ${ }^{65}$ whereas in dogs, horses, and donkeys, T-M1 seemed to 433 be a relatively minor metabolite. ${ }^{72-74}$ These animals produce less T-M1 and more T-M2, as fathead 434 minnows do. Differences in metabolism of tramadol between different aquatic organisms as well as 435 fish species can be a question of future interest.

436 A comparison of norfluoxetine ( $N$-desmethyl fluoxetine)/fluoxetine concentration ratios in 437 plasma of fish with literature values reported in plasma of fish, rodents, and human beings is shown 
438 in Table S6 (Supporting Information) and Figure 3 (B). In our previous study ${ }^{40}$, in which fathead 439 minnows were exposed to fluoxetine at water concentrations ranging from 0.1 to $64 \mu \mathrm{g} \mathrm{L}^{-1}$, we 440 found a change in the slope of the linear regression between water and fish plasma concentrations 441 when water concentrations exceeded $16 \mu \mathrm{g} \mathrm{L}^{-1}$. This variation in slope occurred simultaneously 442 with the decrease of norfluoxetine/fluoxetine concentration ratios. Those results were also 443 confirmed in the present study (Figure S1, Supporting Information), and are likely due to the 444 saturation and/or inhibition of the enzymatic system involved in fluoxetine metabolism. Such a 445 process has also been well documented in both humans and rodents at similar plasma 446 concentrations. ${ }^{32,75-78}$ In clinical studies and in vivo rodent studies, norfluoxetine/fluoxetine 447 concentration ratios were approximately 1.0 at therapeutic plasma concentration ranges (120-500 $\left.448 \mathrm{ng} \mathrm{mL}{ }^{-1}\right)^{33}$, showing that concentrations of circulating fluoxetine and norfluoxetine are mostly in 449 the same range ${ }^{75-77,79}$. On the other hand, norfluoxetine/fluoxetine concentration ratios for fathead 450 minnows were $3.0 \pm 1.1$ when plasma fluoxetine levels were $390 \pm 240 \mathrm{ng} \mathrm{mL}^{-1}$. Nakamura and 451 coworkers $^{41}$ previously observed norfluoxetine/fluoxetine ratios between 2.2 and 8.5 for Japanese 452 medaka (Oryzias latipes) exposed to fluoxetine at $14-15 \mu \mathrm{g} \mathrm{L}^{-1}$ water for 30 days at water $\mathrm{pH}$ of 453 7-9. From these results, it is possible to hypothesise that fish are able to transform fluoxetine into 454 norfluoxetine more efficiently than humans do, as suggested by the higher norfluoxetine/fluoxetine 455 ratios.

456 In humans, tramadol primarily undergoes CYP 2D6-catalyzed $O$-demethylation to the active 457 metabolite T-M1, and CYP 2B6 and 3A4-catalyzed $N$-demethylation to inactive metabolite T-M2. 458 T-M1 and T-M2 are further metabolized to the following metabolites: $N, N$-didesmethyl tramadol, $459 N, N, O$-tridesmethyl tramadol, and $N, O$-desmethyl tramadol. All these metabolites are finally 460 conjugated with glucuronic acid and sulfate to be excreted by the kidneys. ${ }^{30}$ In the case of 461 fluoxetine, CYP 2D6, 2C9, 2C19, and 3A4 are responsible for $N$-demethylation of fluoxetine in 462 humans; beside, fluoxetine undergoes direct conjugation with glucuronic acid. ${ }^{32,78,80}$ Due to an 463 apparent deficiency of 2B, 2C, and 2D homologues of CYPs in fish, it is plausible to hypothesise 
464 that other fish-specific CYP 2 subfamilies (e.g., CYP 2K and 2Y) are involved in the metabolism of 465 tramadol and fluoxetine in fish. It is also important to consider that 47 CYP2 genes were identified 466 in zebrafish, in contrast to 16 in humans. ${ }^{31}$ The quantitative functional properties of those isoforms 467 remain largely unknown; nonetheless, their characterization remains an important research task for 468 the future, as this information would dramatically increase the accuracy and predictive power of 469 pharmacokinetic models for fish species. So far, one possible interpretation of the metabolite/parent concentration ratios obtained for tramadol in the present study is that CYP 2 subfamilies-catalyzed $O$-demethylation occurs slower than CYP 3 subfamilies-catalyzed $N$-demethylation in fish.

The comparison of metabolite/parent concentration ratios in different animals requires a note of caution because of differences in induction/inhibition/saturation dynamics of metabolic enzymes. Additionally, the results discussed here were obtained using fish exposed to the drug via water. This type of administration route results in sustained levels of the drug in the blood for the duration of the experiment, as drug uptake via the gills is continuous. This exposure scenario is to some extent different than drug administration in humans and other mammal species, which typically occur with lower intra-day frequency, resulting in plasma concentrations that display more pronounced oscillatory dynamics than in fish. At this stage, we do not know the exact quantitative implications of these different exposure dynamics on the metabolic capabilities between fish and mammal species.

482 Tramadol is a pro-drug that requires metabolic activation to become a pharmacologically active molecule (i.e., $\mu$-opioid receptor agonist). Unless fish are able to metabolise the parent tramadol into T-M1, the opioid receptor-mediated effects (e.g., sedative and analgesic effects) on fish would not be observed. Considering the fact that approximately $10 \%$ of all approved small molecular drugs on the global market are classified as pro-drugs, ${ }^{81}$ it is scientifically worthwhile for the environmental risk assessment to understand drug metabolism in aquatic organisms such as fish. In addition, it is meaningful to measure the concentrations of these active metabolites as well as 
490

491

492

493

494

495

496

497

498

499

500

501

502

503

504

505

506

507

508

509

510

511

512

513

514

515

occurrence and fate of active metabolites in the aquatic environment. There is, for example, a small amount of data on tramadol, which reported T-M1/tramadol concentration ratios ranging from 0.1 to 2.9 in WWTP effluents in Germany. ${ }^{21}$

In conclusion, the main finding of this study is that the teleost fish fathead minnow metabolises tramadol in a similar manner to humans and other mammalian species, and that concentration ratios of T-M1 to tramadol observed in the fish were comparable to the lower range of values previously reported in humans, and much lower than the values previously found in mouse, rat, and cat, which may be highly relevant when attempting to predict the environmental risk of this compound. The presence of T-M1 in fish suggest that the opioid receptor-mediated effects (e.g., sedative and analgesic effects) of tramadol would occur in fish once internal T-M1 concentrations are high enough to produce these effects. It is therefore likely that other opioids administered as pro-drugs, such as codeine and oxycodone, will be effective in fish, because in humans both have to be activated ( $O$-demethylated) into their active metabolites morphine and oxymorphine, respectively. The amount of information available so far on drug metabolism in fish, although limited, supports the contention that fish metabolise human pharmaceuticals in the same way as humans and other mammalian species do. For example, the cardiovascular drug clofibric acid is metabolised by zebrafish embryos to at least 18 metabolites, ${ }^{82}$ the calcium channel blocker diltiazem is metabolised to at least 8 metabolites, ${ }^{83}$ and the anti-epileptic carbamazepine is metabolised to two or more metabolites, ${ }^{10}$ all of which have been identified in mammals administered these drugs. We are aware of only two studies to date in which metabolism of a pro-drug by fish has been studied. Both studies $^{84,85}$ showed that the glucocorticoid pro-drug beclomethasone dipropionate is readily metabolised by fish to the active moieties beclomethasone 17-monopropionate and beclomethasone, just as it is in humans and other mammalian species. Thus, if no evidence of the metabolism of a pro-drug is available to utilise in an environmental risk assessment, it seems reasonable to assume that fish will metabolise the pro-drug to the same active metabolites produced in mammals, as a worst-case assumption. This realisation strengthens the arguments for utilizing the read-across 
516 hypothesis ${ }^{13,19}$ in the environmental risk assessment of pharmaceuticals.

\section{ACKNOWLEDGMENTS}

519 We would like to thank members of the Ecotoxicology Research Group, Brunel University 520 London, particularly J. Walker, N. Brodigan, and A. Ferreira for fish husbandry, and T. Thrupp, E. 521 Lawton, and A. Baynes for fish sampling. The research at Brunel University London was internally 522 funded by the university. This study was also supported by the Ministry of Education, Culture, 523 Sports, Science and Technology, Japan (MEXT) to a project on Joint Usage/Research Center524 Leading Academia in Marine and Environment Pollution Research (LaMer), and Research 525 Fellowships from the Japan Society for the Promotion of Science (JSPS) for Young Scientists in 526 Japan (PD) provided to R. Tanoue (26-2800), Grants-in-Aid (KAKENHI) for Scientific Research 527 (A) (25257403), Scientific Research (A) (16H01784). This study was also funded by the Sasakawa 528 Scientific Research Grant from The Japan Science Society.

\section{ASSOCIATED CONTENT}

\section{Supporting Information}

532 Additional tables (Tables S1-S6), figure (Figure S1), and text supporting sample extraction 533 procedures, parameters for the instrumental analysis, quality assurance and quality control. This 534 material is available free of charge via the Internet at http://pubs.acs.org.

\section{AUTHOR INFORMATION}

\section{Corresponding Author}

538 *E-mail: rumi.tanoue.lw@gmail.com; tanoue.rumi.lw@ehime-u.ac.jp; Phone: +81 899278174

539 Notes

540 The authors declare no competing financial interest. 
542

543

544

545

546

547

548

549

550

551

552

553

554

555

556

557

558

559

560

561

562

563

564

565

566

567

\section{REFERENCES}

(1) Aus der Beek, T.; Weber, F.-A.; Bergmann, A.; Hickmann, S.; Ebert, I.; Hein, A.; Küster, A. Pharmaceuticals in the environment - global occurrences and perspectives. Environmental Toxicology and Chemistry 2016, 35, 823-835.

(2) Petrie, B.; Barden, R.; Kasprzyk-Hordern, B. A review on emerging contaminants in wastewaters and the environment: Current knowledge, understudied areas and recommendations for future monitoring. Water Research 2015, 72, 3-27.

(3) Luo, Y.; Guo, W.; Ngo, H. H.; Nghiem, L. D.; Hai, F. I.; Zhang, J.; Liang, S.; Wang, X. C. A review on the occurrence of micropollutants in the aquatic environment and their fate and removal during wastewater treatment. The Science of the Total Environment 2014, 473-474, 619-641.

(4) Loos, R.; Carvalho, R.; António, D. C.; Comero, S.; Locoro, G.; Tavazzi, S.; Paracchini, B.; Ghiani, M.; Lettieri, T.; Blaha, L.; et al. EU-wide monitoring survey on emerging polar organic contaminants in wastewater treatment plant effluents. Water Research 2013, 47, 6475-6487.

(5) Tanoue, R.; Nomiyama, K.; Nakamura, H.; Kim, J.-W.; Isobe, T.; Shinohara, R.; Kunisue, T.; Tanabe, S. Uptake and tissue distribution of pharmaceuticals and personal care products in wild fish from treated-wastewater-impacted streams. Environmental Science \& Technology 2015, 49, 11649-11658.

(6) Huerta, B.; Jakimska, A.; Gros, M.; Rodríguez-Mozaz, S.; Barceló, D. Analysis of multi-class pharmaceuticals in fish tissues by ultra-high-performance liquid chromatography tandem mass spectrometry. Journal of Chromatography A 2013, 1288, 63-72.

(7) Du, B.; Haddad, S. P.; Luek, A.; Scott, W. C.; Saari, G. N.; Burket, S. R.; Breed, C. S.; Kelly, M.; Broach, L.; Rasmussen, J. B.; et al. Bioaccumulation of human pharmaceuticals in fish across habitats of a tidally influenced urban bayou. Environmental Toxicology and Chemistry 2016, 35, 966-974. 
568 (8) Xie, Z.; Lu, G.; Liu, J.; Yan, Z.; Ma, B.; Zhang, Z.; Chen, W. Occurrence, bioaccumulation, and trophic magnification of pharmaceutically active compounds in Taihu Lake, China. Chemosphere 2015, 138, 140-147.

(9) Valdés, M. E.; Amé, M. V.; Bistoni, M. de los A.; Wunderlin, D. A. Occurrence and bioaccumulation of pharmaceuticals in a fish species inhabiting the Suquía River basin (Córdoba, Argentina). Science of the Total Environment 2014, 472, 389-396.

(10) Valdés, M. E.; Huerta, B.; Wunderlin, D. A.; Bistoni, M. A.; Barceló, D.; Rodriguez-Mozaz, S. Bioaccumulation and bioconcentration of carbamazepine and other pharmaceuticals in fish under field and controlled laboratory experiments. Evidences of carbamazepine metabolization by fish. Science of the Total Environment 2016, 557-558, 58-67.

(11) Küster, A.; Adler, N. Pharmaceuticals in the environment: scientific evidence of risks and its regulation. Philosophical Transactions of the Royal Society B: Biological Sciences 2014, 369,

(12) Fent, K.; Weston, A. A.; Caminada, D. Ecotoxicology of human pharmaceuticals. Aquatic toxicology 2006, 76, 122-159.

(13) Rand-Weaver, M.; Margiotta-Casaluci, L.; Patel, A.; Panter, G. H.; Owen, S. F.; Sumpter, J. P. The read-across hypothesis and environmental risk assessment of pharmaceuticals. Environmental Science \& Technology 2013, 47, 11384-11395.

(14) Escher, B. I.; Ashauer, R.; Dyer, S.; Hermens, J. L. M.; Lee, J. H.; Leslie, H. A.; Mayer, P.; understanding tissue residue toxicity and internal effect concentrations of organic chemicals. Integrated Environmental Assessment and Management 2011, 7, 28-49. 
594 (16) Hutchinson, T. H.; Madden, J. C.; Naidoo, V.; Walker, C. H. Comparative metabolism as a key driver of wildlife species sensitivity to human and veterinary pharmaceuticals. Philosophical Transactions of the Royal Society B: Biological Sciences 2014, 369, 1-9.

(17) Brox, S.; Seiwert, B.; Kuester, E.; Reemtsma, T. Toxicokinetics of polar chemicals in zebrafish embryo (Danio rerio): influence of physico-chemical properties and of biological processes. Environmental Science \& Technology 2016, 50, 10264-10272.

(18) Gunnarsson, L.; Jauhiainen, A.; Kristiansson, E.; Nerman, O.; Larsson, D. G. J. Evolutionary conservation of human drug targets in organisms used for environmental risk assessments.

603

604

605

606

607

608

609

610 Environmental Science \& Technology 2008, 42, 5807-5813.

(19) Huggett, D. B.; Cook, J. C.; Ericson, J. F.; Williams, R. T. Theoretical model for prioritizing potential impacts of human pharmaceuticals to fish. Human and Ecological Risk Assessment 2003, 9, 1789-1799.

(20) Kasprzyk-Hordern, B.; Dinsdale, R. M.; Guwy, A. J. The removal of pharmaceuticals, personal care products, endocrine disruptors and illicit drugs during wastewater treatment and its impact on the quality of receiving waters. Water Research 2009, 43, 363-380.

(21) Rúa-Gómez, P. C.; Püttmann, W. Occurrence and removal of lidocaine, tramadol, venlafaxine, and their metabolites in German wastewater treatment plants. Environmental Science and Pollution Research 2012, 19, 689-699.

(22) Baker, D. R.; Kasprzyk-Hordern, B. Spatial and temporal occurrence of pharmaceuticals and illicit drugs in the aqueous environment and during wastewater treatment: New developments. Science of the Total Environment 2013, 454-455, 442-456.

(23) Petrie, B.; Youdan, J.; Barden, R.; Kasprzyk-Hordern, B. Multi-residue analysis of 90 emerging contaminants in liquid and solid environmental matrices by ultra-high-performance liquid chromatography tandem mass spectrometry. Journal of Chromatography A 2016, 1431, $64-78$.

(24) Rúa-Gómez, P. C.; Püttmann, W. Degradation of lidocaine, tramadol, venlafaxine and the 
metabolites O-desmethyltramadol and O-desmethylvenlafaxine in surface waters. Chemosphere 2013, 90, 1952-1959.

(25) Li, Z.; Sobek, A.; Radke, M. Fate of pharmaceuticals and their transformation products in four small European rivers receiving treated wastewater. Environmental Science and Technology 2016, 50, 5614-5621.

(26) Kasprzyk-Hordern, B.; Dinsdale, R. M.; Guwy, A. J. The occurrence of pharmaceuticals, personal care products, endocrine disruptors and illicit drugs in surface water in South Wales, UK. Water Research 2008, 42, 3498-3518.

(27) Kusari, S.; Tatsimo, S. J. N.; Zühlke, S.; Spiteller, M. Synthetic Origin of Tramadol in the Environment. Angewandte Chemie - International Edition 2016, 55, 240-243.

(28) Bergheim, M.; Gieré, R.; Kümmerer, K. Biodegradability and ecotoxicity of tramadol, ranitidine, and their photoderivatives in the aquatic environment. Environmental Science and Pollution Research 2012, 19, 72-85.

(29) Li, Z.; Sobek, A.; Radke, M. Flume experiments to investigate the environmental fate of pharmaceuticals and their transformation products in streams. Environmental Science and Technology 2015, 49, 6009-6017.

(30) Vazzana, M.; Andreani, T.; Fangueiro, J.; Faggio, C.; Silva, C.; Santini, A.; Garcia, M. L.; Silva, A. M.; Souto, E. B. Tramadol hydrochloride: pharmacokinetics, pharmacodynamics, adverse side effects, co-administration of drugs and new drug delivery systems. Biomedicine \& Pharmacotherapy 2015, 70, 234-238.

(31) Goldstone, J. V; McArthur, A. G.; Kubota, A.; Zanette, J.; Parente, T.; Jönsson, M. E.; Nelson, D. R.; Stegeman, J. J. Identification and developmental expression of the full complement of Cytochrome P450 genes in Zebrafish. BMC genomics 2010, 11, 643.

(32) Hiemke, C.; Härtter, S. Pharmacokinetics of selective serotonin reuptake inhibitors. Pharmacology \& Therapeutics 2000, 85, 11-28.

(33) Schulz, M.; Iwersen-Bergmann, S.; Andresen, H.; Schmoldt, A. Therapeutic and toxic blood 
concentrations of nearly 1,000 drugs and other xenobiotics. Critical Care 2012, 16, R136.

(34) Schreiber, R.; Gündel, U.; Franz, S.; Küster, A.; Rechenberg, B.; Altenburger, R. Using the fish plasma model for comparative hazard identification for pharmaceuticals in the environment by extrapolation from human therapeutic data. Regulatory Toxicology and Pharmacology 2011, 61, 261-275.

(35) Roos, V.; Gunnarsson, L.; Fick, J.; Larsson, D. G. J.; Rudén, C. Prioritising pharmaceuticals for environmental risk assessment: Towards adequate and feasible first-tier selection. The Science of the Total Environment 2012, 421-422, 102-110.

(36) Fitzsimmons, P. N.; Fernandez, J. D.; Hoffman, A. D.; Butterworth, B. C.; Nichols, J. W. Branchial elimination of superhydrophobic organic compounds by rainbow trout (Oncorhynchus mykiss). Aquatic Toxicology 2001, 55, 23-34.

(37) Baumer, A.; Bittermann, K.; Klüver, N.; Escher, B. I. Baseline toxicity and ion-trapping models to describe the $\mathrm{pH}$-dependence of bacterial toxicity. Environmental Science: Processes \& Impacts 2017, 19, 901-916.

(38) Valenti, T. W.; Gould, G. G.; Berninger, J. P.; Connors, K. A.; Keele, N. B.; Prosser, K. N.; Brooks, B. W. Human therapeutic plasma levels of the selective serotonin reuptake inhibitor (SSRI) sertraline decrease serotonin reuptake transporter binding and shelter-seeking behavior in adult male fathead minnows. Environmental Science \& Technology 2012, 46, $2427-2435$.

(39) Huerta, B.; Margiotta-Casaluci, L.; Rodriguez-Mozaz, S.; Scholze, M.; Winter, M. J.; Barcelo, D.; Sumpter, J. P. Anti-anxiety drugs and fish behaviour: Establishing the link between internal concentrations of oxazepam and behavioural effects. Environmental Toxicology and Chemistry 2016, 35, 2782-2790.

(40) Margiotta-Casaluci, L.; Owen, S. F.; Cumming, R. I.; de Polo, A.; Winter, M. J.; Panter, G. H.; Rand-Weaver, M.; Sumpter, J. P. Quantitative cross-species extrapolation between humans and fish: the case of the anti-depressant fluoxetine. PLOS ONE 2014, 9, e110467. 
672 (41) Nakamura, Y.; Yamamoto, H.; Sekizawa, J.; Kondo, T.; Hirai, N.; Tatarazako, N. The effects of $\mathrm{pH}$ on fluoxetine in Japanese medaka (Oryzias latipes): acute toxicity in fish larvae and bioaccumulation in juvenile fish. Chemosphere 2008, 70, 865-873.

(42) Meredith-Williams, M.; Carter, L. J.; Fussell, R.; Raffaelli, D.; Ashauer, R.; Boxall, A. B. A. Uptake and depuration of pharmaceuticals in aquatic invertebrates. Environmental Pollution 2012, 165, 250-258.

(43) Winter, M. J.; Lillicrap, A. D.; Caunter, J. E.; Schaffner, C.; Alder, A. C.; Ramil, M.; Ternes, T. A.; Giltrow, E.; Sumpter, J. P.; Hutchinson, T. H. Defining the chronic impacts of atenolol on embryo-larval development and reproduction in the fathead minnow (Pimephales promelas). Aquatic Toxicology 2008, 86, 361-369.

(44) Nallani, G.; Venables, B.; Constantine, L.; Huggett, D. Comparison of measured and predicted bioconcentration estimates of pharmaceuticals in fish plasma and prediction of chronic risk. Bulletin of Environmental Contamination and Toxicology 2016, 96, 580-584.

(45) Owen, S. F.; Huggett, D. B.; Hutchinson, T. H.; Hetheridge, M. J.; Kinter, L. B.; Ericson, J. F.; Sumpter, J. P. Uptake of propranolol, a cardiovascular pharmaceutical, from water into fish plasma and its effects on growth and organ biometry. Aquatic Toxicology 2009, 93, 217-224.

(46) Bittermann, K.; Spycher, S.; Endo, S.; Pohler, L.; Huniar, U.; Goss, K.-U.; Klamt, A. Prediction of Phospholipid-Water Partition Coefficients of Ionic Organic Chemicals Using the Mechanistic Model COSMO mic. The Journal of Physical Chemistry B 2014, 118, $14833-14842$.

(47) Escher, B. I.; Schwarzenbach, R. P. Evaluation of liposome - water partitioning of organic acids and bases . 2 . Comparison of dxperimental determination methods. Environmental Science \& Technology 2000, 34, 3962-3968.

(48) Smejtek, P.; Wang, S. Distribution of hydrophobic ionizable xenobiotics between water and lipid membranes: Pentachlorophenol and pentachlorophenate. A comparison with octanol-water partition. Archives of Environmental Contamination and Toxicology 1993, 25, 
698

699

700

701

702

703

704

705

706

707

708

709

710

711

712

713

714

715

716

717

718

719

720

721

722

723

394-404.

(49) Escher, B. I.; Snozzi, M.; Schwarzenbach, R. P. Uptake, speciation, and uncoupling activity of substituted phenols in energy transducing membranes. Environmental Science and Technology 1996, 30, 3071-3079.

(50) T’Jollyn, H.; Snoeys, J.; Colin, P.; Van Bocxlaer, J.; Annaert, P.; Cuyckens, F.; Vermeulen, A.; Van Peer, A.; Allegaert, K.; Mannens, G.; et al. Physiology-based ivive predictions of tramadol from in vitro metabolism data. Pharmaceutical Research 2015, 32, 260-274.

(51) Bertelsen, S. L.; Hoffman, A. D.; Gallinat, C. A.; Elonen, C. M.; Nichols, J. W. Evaluation of $\log$ Kow and tissue lipid content as predictors of chemical partitioning to fish tissues. Environmental Toxicology 1998, 17, 1447-1455.

(52) Trapp, S.; Horobin, R. W. A predictive model for the selective accumulation of chemicals in tumor cells. European biophysics journal : EBJ 2005, 34, 959-966.

(53) Endo, S.; Escher, B. I.; Goss, K.-U. Capacities of membrane lipids to accumulate neutral organic chemicals. Environmental Science \& Technology 2011, 45, 5912-5921.

(54) Ulrich, N.; Endo, S.; Brown, T. N.; Watanabe, N.; Bronner, G.; Abraham, M. H.; Goss, K.-U. UFZ-LSER database v 3.2 [Internet], Leipzig, Germany, Helmholtz Centre for Environmental Research-UFZ. 2017 [accessed Augest 25th, 2017].Available from http://www.ufz.de/lserd.

(55) Lehmann, K. A.; Kratzenberg, U.; Schroeder-Bark, B.; Horrichs-Haermeyer, G.

Postoperative patient-controlled analgesia with tramadol: analgesic efficacy and minimum effective concentrations. The Clinical Journal of Pain 1990, 6, 212-220.

(56) Grond, S.; Sablotzki, A. Clinical pharmacology of tramadol. Clinical Pharmacokinetics 2004, 43, 879-923.

(57) Wu, W. N.; McKown, L. A.; Liao, S. Metabolism of the analgesic drug ULTRAM ${ }^{\circledR}$ (tramadol hydrochloride) in humans: API-MS and MS/MS characterization of metabolites. Xenobiotica 2002, 32, 411-425.

(58) Fick, J.; Lindberg, R. H.; Parkkonen, J.; Arvidsson, B.; Tysklind, M.; Larsson, D. G. J. 
Therapeutic levels of levonorgestrel detected in blood plasma of fish: results from screening rainbow trout exposed to treated sewage effluents. Environmental Science \& Technology 2010, 44, 2661-2666.

(59) Nichols, J. W.; Du, B.; Berninger, J. P.; Connors, K. A.; Chambliss, C. K.; Erickson, R. J.; Hoffman, A. D.; Brooks, B. W. Observed and modeled effects of $\mathrm{pH}$ on bioconcentration of diphenhydramine, a weakly basic pharmaceutical, in fathead minnows. Environmental Toxicology and Chemistry 2015, 34, 1425-1435.

(60) Karlsson, M. V.; Carter, L. J.; Agatz, A.; Boxall, A. B. A. Novel approach for characterizing pH-dependent uptake of ionizable chemicals in aquatic organisms. Environmental Science \& Technology 2017, 51, 6965-6971.

(61) Zhao, J. L.; Furlong, E. T.; Schoenfuss, H. L.; Kolpin, D. W.; Bird, K. L.; Feifarek, D. J.; Schwab, E. A.; Ying, G. G. Uptake and disposition of select pharmaceuticals by bluegill exposed at constant concentrations in a flow-through aquatic exposure system. Environmental Science \&Technology 2017, 51, 4434-4444.

(62) Boström, M. L.; Berglund, O. Influence of pH-dependent aquatic toxicity of ionizable pharmaceuticals on risk assessments over environmental $\mathrm{pH}$ ranges. Water Research 2015, 72, $154-161$.

(63) Kitamura, A.; Higuchi, K.; Okura, T.; Deguchi, Y. Transport Characteristics of Tramadol in the Blood-Brain Barrier. Journal of Pharmaceutical Sciences 2014, 103, 3335-3341.

(64) Tao, Q.; Stone, D. J.; Borenstein, M. R.; Jean-bart, V.; Codd, E. E.; Coogan, T. P.; Desai-krieger, D.; Liao, S.; Raffa, R. B. Gas chromatographic method using nitrogen phosphorus detection for the measurement of tramadol and its O-desmethyl metabolite in plasma and brain tissue of mice and rats. Journal of Chromatography B 2001, 763, 165-171.

(65) Tao, Q.; Stone, D. J.; Borenstein, M. R.; Codd, E. E.; Coogan, T. P.; Desai-Krieger, D.; Liao, S.; Raffa, R. B. Differential tramadol and O-desmethyl metabolite levels in brain vs. plasma of mice and rats administered tramadol hydrochloride orally. Journal of Clinical Pharmacy 
and Therapeutics 2002, 27, 99-106.

751

752

753

754

755

756

757

758

759

760

761

762

763

764

765

766

767

768

769

770

771

772

773

774

775

(66) Sheikholeslami, B.; Hamidi, M.; Lavasani, H.; Sharifzadeh, M.; Rouini, M. Lack of evidence for involvement of P-glycoprotein in brain uptake of the centrally acting analgesic, tramadol in the rat. Journal of Pharmaceutical Sciences 2012, 15, 606-615.

(67) Bastami, S.; Haage, P.; Kronstrand, R.; Kugelberg, F. C.; Zackrisson, A.-L.; Uppugunduri, S. Pharmacogenetic aspects of tramadol pharmacokinetics and pharmacodynamics after a single oral dose. Forensic Science International 2014, 238, 125-132.

(68) de Moraes, N. V.; Lauretti, G. R.; Napolitano, M. N.; Santos, N. R.; Godoy, A. L. P. C.; Lanchote, V. L. Enantioselective analysis of unbound tramadol, O-desmethyltramadol and $\mathrm{N}$-desmethyltramadol in plasma by ultrafiltration and LC-MS/MS: Application to clinical pharmacokinetics. Journal of Chromatography B 2012, 880, 140-147.

(69) Campanero, M. A.; García-Quetglas, E.; Sádaba, B.; Azanza, J. R. Simultaneous stereoselective analysis of tramadol and its primary phase I metabolites in plasma by liquid chromatography: Application to a pharmacokinetic study in humans. Journal of Chromatography A 2004, 1031, 219-228.

(70) Ardakani, Y. H.; Rouini, M.-R. Pharmacokinetics of tramadol and its three main metabolites in healthy male and female volunteers. Biopharmaceutics \& Drug Disposition 2007, 28, $527-534$.

(71) Zhuo, H.; Jin, H.; Peng, H.; Huang, H. Distribution, pharmacokinetics and primary metabolism model of tramadol in zebrafish. Molecular Medicine Reports 2016, 14, $5644-5652$.

(72) Giorgi, M.; Del Carlo, S.; Sgorbini, M.; Saccomanni, G. Pharmacokinetics of tramadol and its metabolites M1, M2, and M5 in donkeys after intravenous and oral immediate release single-dose administration. Journal of Equine Veterinary Science 2009, 29, 569-574.

(73) Giorgi, M.; Del Carlo, S.; Saccomanni, G.; Łebkowska-Wieruszewska, B.; Kowalski, C. J. Pharmacokinetic and urine profile of tramadol and its major metabolites following oral 
776

777

778

779

780

781

782

783

784

785

786

787

788

789

790

791

792

793

794

795

796

797

798

799

800

801

immediate release capsules administration in dogs. Veterinary Research Communications 2009, 33, 875-885.

(74) Giorgi, M.; Soldani, G.; Manera, C.; Ferrarini, P. L.; Sgorbini, M.; Saccomanni, G. Pharmacokinetics of tramadol and its metabolites M1, M2 and M5 in horses following intravenous, immediate release (fasted/fed) and sustained release single dose administration. Journal of Equine Veterinary Science 2007, 27, 481-488.

(75) Reis, M.; Aamo, T.; Spigset, O.; Ahlner, J. Serum concentrations of antidepressant drugs in a naturalistic setting: compilation based on a large therapeutic drug monitoring database. Therapeutic Drug Monitoring 2009, 31, 42-56.

(76) Unceta, N.; Barrondo, S.; de Azúa, I. R.; Gómez-Caballero, A.; Goicolea, M. A.; Sallés, J.; Barrio, R. J. Determination of fluoxetine, norfluoxetine and their enantiomers in rat plasma and brain samples by liquid chromatography with fluorescence detection. Journal of Chromatography B: Analytical Technologies in the Biomedical and Life Sciences 2007, 852, $519-528$.

(77) Bourdeaux, R.; Desor, D.; Lehr, P. R.; Younos, C.; Capolaghi, B. Effects of fluoxetine and norfluoxetine on 5-hydroxytryptamine metabolism in blood platelets and brain after administration to rats. The Journal of Pharmacy and Pharmacology 1998, 50, 1387-1392.

(78) Margolis, J. M.; O’Donnell, J. P.; Mankowski, D. C.; Ekins, S.; Obach, R. S. (R)-, (S)-, and Racemic Fluoxetine N-Demethylation by Human Cytochrome P450 Enzymes. Drug Metabolism and Disposition 2000, 28, 1187-1191.

(79) Amsterdam, J. D.; Fawcett, J.; Quitkin, F. M.; Reimherr, F. W.; Rosenbaum, J. F.; Michelson, D.; Hornig-Rohan, M.; Beasley, C. M. Fluoxetine and norfluoxetine plasma concentrations in major depression: A multicenter study. American Journal of Psychiatry 1997, 154, 963-969.

(80) Pypendop, B. H.; Ilkiw, J. E. Pharmacokinetics of tramadol, and its metabolite O-desmethyl-tramadol, in cats. Journal of Veterinanry Pharmacology and Therapeutics 2007, $31,52-59$. 
802 (81) Huttunen, K. M.; Raunio, H.; Rautio, J. Prodrugs - from serendipity to rational design.

803

804

805

806

807

808

809

810

811

812

813

814

815

816

817

818

819

820

821
Pharmacological Reviews 2011, 63, 750-771.

(82) Brox, S.; Seiwert, B.; Haase, N.; Küster, E.; Reemtsma, T. Metabolism of clofibric acid in zebrafish embryos (Danio rerio) as determined by liquid chromatography-high

resolution-mass spectrometry. Comparative Biochemistry and Physiology Part - C:

Toxicology and Pharmacology 2016, 185-186, 20-28.

(83) Steinbach, C.; Grabic, R.; Fedorova, G.; Koba, O.; Golovko, O.; Grabicova, K.; Kroupova, H. K. Bioconcentration, metabolism and half-life time of the human therapeutic drug diltiazem in rainbow trout Oncorhynchus mykiss. Chemosphere 2016, 144, 154-159.

(84) Carney Almroth, B. M.; Gunnarsson, L. M.; Cuklev, F.; Fick, J.; Kristiansson, E.; Larsson, J. D. G. Waterborne beclomethasone dipropionate affects the physiology of fish while its metabolite beclomethasone is not taken up. Science of the Total Environment 2015, 511, $37-46$.

(85) Margiotta-Casaluci, L.; Owen, S. F.; Huerta, B.; Rodríguez-Mozaz, S.; Kugathas, S.; Barceló, D.; Rand-Weaver, M.; Sumpter, J. P. Internal exposure dynamics drive the Adverse Outcome Pathways of synthetic glucocorticoids in fish. Scientific Reports 2016, 6, 21978. 

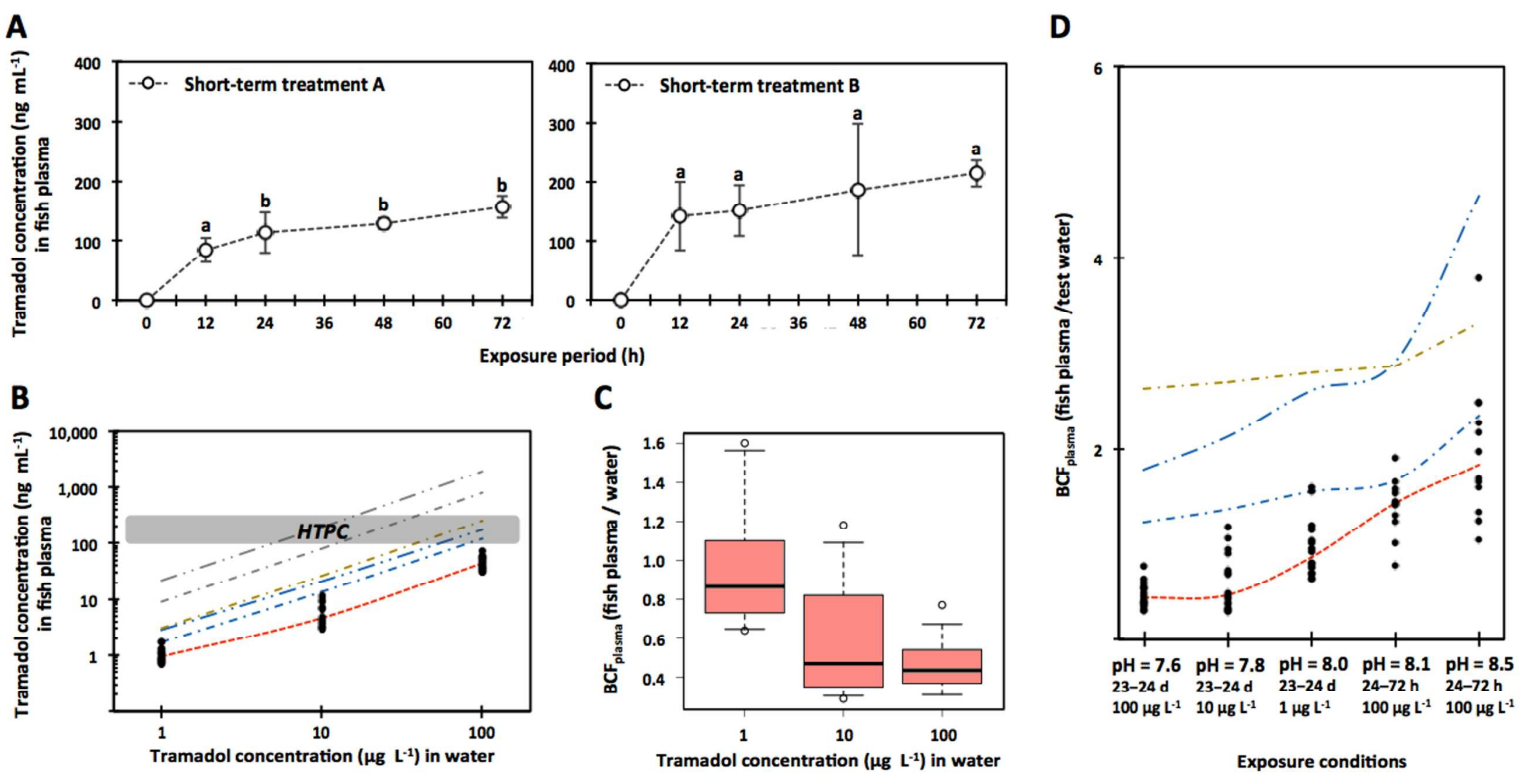

822

823 Figure 1. Plasma concentrations and $\mathbf{B C F}$ plasma (fish plasma/water concentration ratios) of

824 tramadol in the fathead minnow. (A) Time-course of tramadol concentrations (mean $\pm \mathrm{SD}, n=4$ )

825 in plasma of fish exposed to $100 \mu \mathrm{g} \mathrm{L}^{-1}$ of tramadol at water $\mathrm{pH} 8.1$ (short-term treatment $\mathrm{A}$ ) or 8.5

826 (short-term treatment B). Different letters above error bars denote significant differences between

827 time periods ( $p<0.05$, one-way ANOVA followed by a post hoc Tukey HSD test). (B) Measured

828 (red dashed line, median, $n=16$; black dots, individuals) and predicted (dot-dot-dashed line and

829 dot-dashed line) plasma concentrations of tramadol after 23-24 days exposure. The grey

830 dot-dot-dashed line and dot-dashed line were calculated by using the highest and the lowest $\log K_{\mathrm{ow}}$,

831 respectively; the yellow dot-dashed line was calculated by using the $\log D_{\text {lipw; the blue }}$

832 dot-dot-dashed line and dot-dashed line were calculated by using the highest and the $\operatorname{lowest} \log D_{\text {ow }}$,

833 respectively (Table S4). The grey area indicates the human therapeutic plasma concentration

834 (HTPC) range (100-300 $\left.\mathrm{ng} \mathrm{mL}^{-1}\right)$. (C) $\mathrm{BCF}_{\text {plasma }}$ values of tramadol at water concentrations of 1

835 (TG-1), 10 (TG-10), and 100 (TG-100) $\mu \mathrm{g} \mathrm{L}^{-1}$. The box plots show 5th (lower whisker), 25th

836 (bottom edge of box), 75th (top edge of box), and 95th (upper whisker) percentiles. The horizontal

837 line in the box represents the median value. The small dots (०) are outliers. (D) pH-dependent

838 measured (red dashed line, median; black dots, individuals) and predicted (dot-dot-dashed line and 
839 dot-dashed line) $\mathrm{BCF}_{\text {plasma }}$ of tramadol after 23-24 days or 24-72-h exposure test. The yellow

840 dot-dashed line was calculated by using the $\log D_{\text {lipw }}$; the blue dot-dot-dashed line and dot-dashed

841 line were calculated by using the highest and the lowest $\log D_{\text {ow }}$, respectively (Table S4).

842

843

844

845

846

847

848

849

850

851

852

853

854

855

856

857

858

859

860

861

862

863

864 

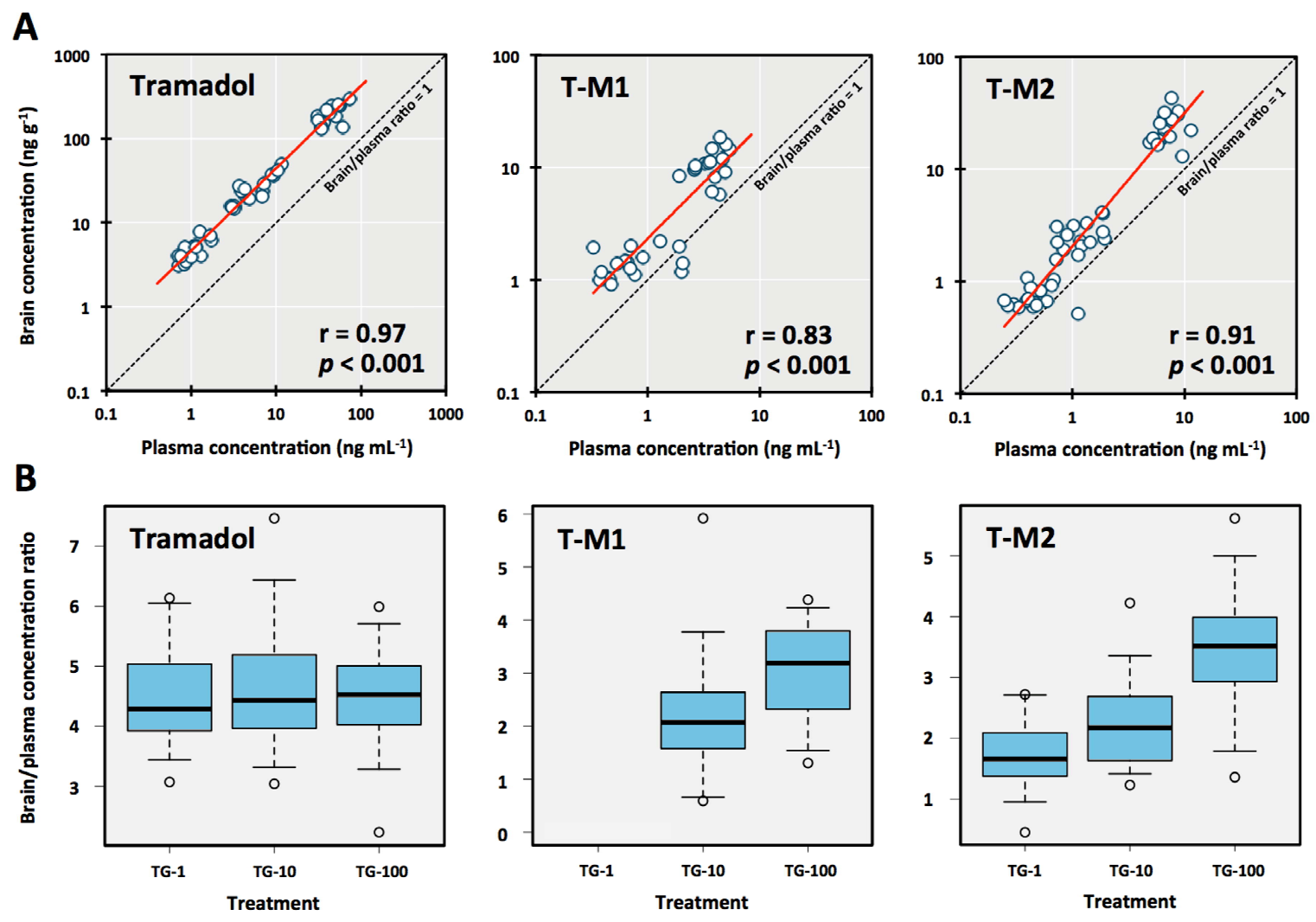

865

Figure 2. Brain concentrations and brain/plasma concentration ratios of tramadol and its between brain and plasma individual fish concentrations of tramadol, T-M1, and T-M2. Y-axis: chemical concentrations in the brain, X-axis: chemical concentrations in the plasma. The dashed line represents an exact match between chemical levels in plasma and brain. (B) Brain/plasma 871 concentration ratios of tramadol, T-M1, and T-M2 at water concentrations of 1 (TG-1), 10 (TG-10), 872 and 100 (TG-100) $\mu \mathrm{g} \mathrm{L} \mathrm{L}^{-1}$. The box plots show 5th (lower whisker), 25th (bottom edge of box), 75th 873 (top edge of box), and 95th (upper whisker) percentiles. The horizontal line in the box represents 874 median value. The small dots $(\circ)$ are outliers. The ratios of T-M1 at water concentrations of $1 \mu \mathrm{g}$ $875 \mathrm{~L}^{-1}$ (TG-1) are not shown due to non-detectable concentrations in both plasma and brain. 
A

Tramadol $\rightarrow$ O-desmethyl tramadol

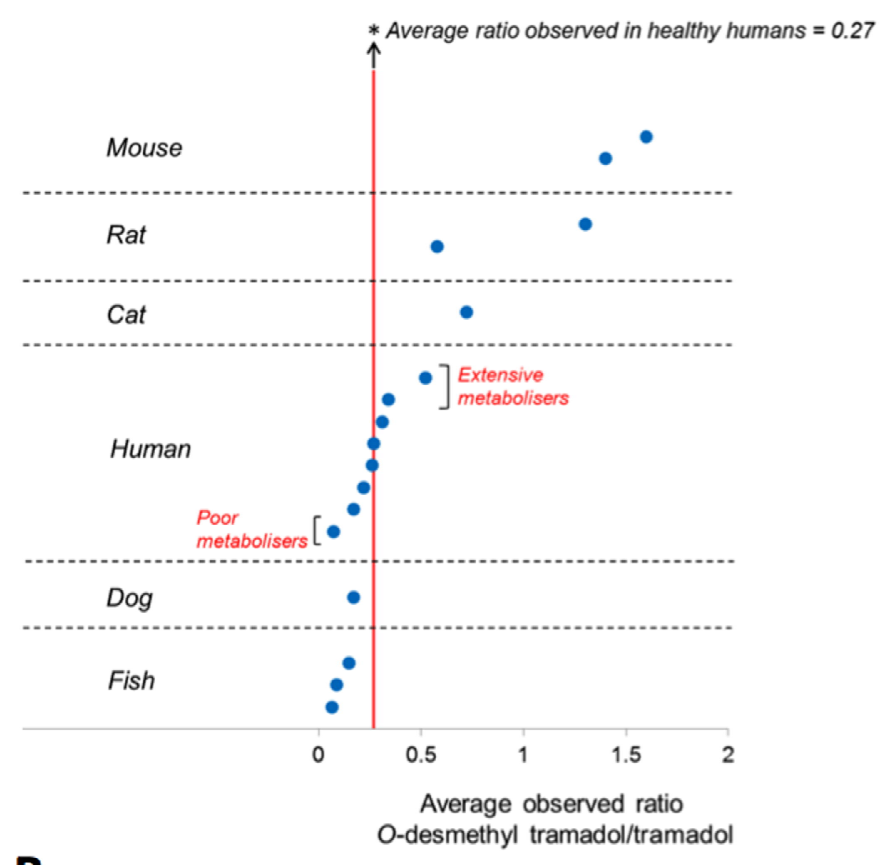

B

\section{Fluoxetine $\rightarrow$ Norfluoxetine}

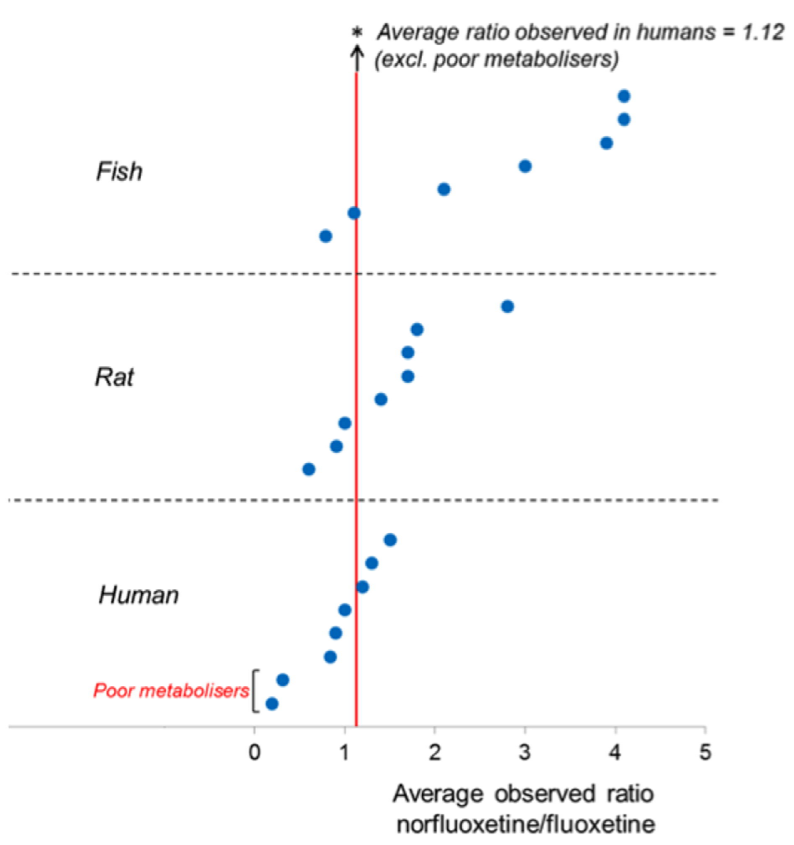

878

879 Figure 3. Inter-species differences in drug metabolism. (A) $O$-desmethyl tramadol/tramadol

880 concentration ratios in plasma of mouse, rat, cat, human, dog, and fish. Fish values were calculated

881 by dividing individual plasma concentrations of $O$-desmethyl tramadol by individual plasma 
882 concentrations of tramadol in the present study. Mammalian values were estimated by dividing the

883 mean plasma concentration of $O$-desmethyl tramadol by the mean plasma concentration of

884 tramadol in the literature mentioned in Table S5 (Supporting Information). (B) Norfluoxetine

885 ( $N$-desmethyl fluoxetine)/fluoxetine concentration ratios in plasma of fish, rat, and human. Fish

886 values were calculated by dividing individual plasma concentrations of norfluoxetine by individual

887 plasma concentrations of fluoxetine in the present study. Mammalian values were estimated by

888 dividing the mean plasma concentration of norfluoxetine by the mean plasma concentration of

889 fluoxetine in the literature mentioned in Table S6 (Supporting Information). 